\title{
Causality of Chronic Suppurative Otitis Media: An Observational Study
}

Zafar Ayaz $^{1}$, Bakht Taj ${ }^{2}$, Maher Sohail Yaseen ${ }^{3}$, Uzma Ishaq ${ }^{4}$, Talha Laique ${ }^{5}$, Jahanzeb Malik ${ }^{6}$, Adnan Baig ${ }^{6}$, Komal Sakhawat ${ }^{6}$

1. Otolaryngology, Timergara DHQ Hospital, Timergara, PAK 2. Otolaryngology, DHQ Hospital Daggar Buner, Buner, PAK 3. Physiology, Dera Ghazi Khan Medical College, Dera Ghazi Khan, PAK 4. Hematology and Medical Oncology, Fauji Foundation Hospital, Rawalpindi, PAK 5. Pharmacology, Lahore Medical and Dental College, Lahore, PAK 6. Cardiology, Rawalpindi Institute of Cardiology, Rawalpindi, PAK

Corresponding author: Jahanzeb Malik, heartdoc86@gmail.com

\section{Abstract}

\section{Objective}

Chronic otorrhoea is a disease of the ear that lasts for more than 6-12 weeks, through a perforated tympanic membrane. We sought to determine the cause of chronic suppurative otitis media (CSOM) at our institute.

\section{Methodology}

Ear swabs taken from enrolled patients ( $\mathrm{n}=139)$ were sent for culture and sensitivity. Statistical analysis was done using Statistical Package for Social Sciences (SPSS), version 26 (IBM Corp., Armonk, NY)

\section{Results}

Common pathogenic bacteria in chronic otitis media observed were Pseudomonas aeruginosa 81 (58\%) while Klebsiella pneumoniae was found in 58 (42\%) of cases.

\section{Conclusion}

We concluded that Pseudomonas aeruginosa was the most common causative agent of CSOM at our institute.

Received 08/01/2020

Review began 08/05/2020 Review ended 08/05/2020 Published 08/18/2020

(c) Copyright 2020

Ayaz et al. This is an open access article distributed under the terms of the Creative Commons Attribution License CC-BY 4.0., which permits unrestricted use, distribution, and reproduction in any medium, provided the original author and source are credited.
Categories: Otolaryngology, Infectious Disease

Keywords: chronic otorrhoea, pseudomonas aeuginosa, klebsiella pneumoniae, otitis media, chronic suppurative otitis media, ear infection

\section{Introduction}

The most common disease in ENT is chronic suppurative otitis media (CSOM). It has been a common health issue among children for centuries. Chronic otorrhoea is a disease of the ear that lasts for more than 6-12 weeks, through a perforated tympanic membrane. Globally, it affects almost 65-100 million people annually. About $60 \%$ of its sufferers experience significant hearing loss mainly because of it [1].

Its prevalence is not known in our region, although the overall prevalence rate of CSOM was found to be $6 \%$ [2]. In Saudi children, chronic ear infection is present in $1.5 \%$ of all ear infections [3]. It is equally distributed among males and females globally [4]. It is associated with complications like hearing impairment, disability, poor scholastic performance, intracranial infections, and acute mastoiditis. It is more common among developing countries. The most common complication of CSOM is acute mastoiditis [5].

Since the majority of these patients are seen by general practitioners, only a limited number of patients have their ear swabs sent for culture and sensitivity. Mostly the treatment is empirical [6].

Staphylococcus epidermidis, Corynebacterium spp., Streptococcus viridans, and Staphylococcus aureus are usually present as commensal flora on the skin of the external auditory canal [7,8]. Pseudomonas and Proteus spp. invade secondarily in cases of otitis externa due to breakage in the skin's natural defense mechanism. With an intact tympanic membrane, the culture swabs from middle ear mucosa show no bacterial growth.

When a defect in the tympanic membrane is present, the flora of the external auditory meatus can be isolated from the middle ear. In CSOM, bacteria may be gram-positive or gram-negative [7]. Complications related to CSOM are due to missed diagnosis and inadequate treatment. The complications include bloody discharge, facial palsy, vertigo, fever, irritability, headache, and deafness [9-11]. 


\section{Cureus}

An effective treatment strategy for reducing the development of its complications is the need of the hour as well as to decrease the number of CSOM in ENT at our tertiary hospitals. In our country, due to the lack of registered cases of CSOM as well as its causative agents, there is a paucity of local studies. In light of this increasing burden, we conducted this study to determine the frequently encountered pathogens for CSOM.

\section{Materials And Methods}

A sample size of 139 patients with a $10 \%$ proportion of the common causative organisms using a $95 \%$ confidence interval and a 5\% margin of error was calculated using a software. Data collection was started after ethical board approval and written consent was taken from all the participants. It was a descriptive cross-sectional study. Swabs were taken from the deep part of the meatus near to the tympanic membrane. They were sent for culture and sensitivity. All the results were recorded.

All the data were processed using the Statistical Package for Social Sciences (SPSS), version 26 (IBM Corp., Armonk, NY). Mean and standard deviation was calculated for age. Frequency and percentages were calculated for categorical variables. Bacterial pathogens were stratified among age and gender to see the effect modifiers.

\section{Results}

A total of 139 patients were enrolled in the study. Among the patients, 92 (66.19\%) were males and 110 (79\%) were children of less than 10 years of age. Baseline characteristics and organisms are shown in Table 1.

\begin{tabular}{|lr}
\hline Baseline Characteristics & $8.32+3.77$ \\
\hline Males $\mathrm{n}(\%)$ & $92(66.19 \%)$ \\
Children $<10$ years $\mathrm{n}(\%)$ & $110(79 \%)$ \\
Organisms & $81(58 \%)$ \\
Pseudomonas Aeruginosa $\mathrm{n}(\%)$ & $58(42 \%)$ \\
\hline Klebsiella Pneumonae $\mathrm{n}(\%)$ &
\end{tabular}

TABLE 1: Baseline characteristics and organisms

Children less than 10 years of age were affected the most and Pseudomonas aeruginosa was the predominant organism seen in this age group $(\mathrm{P}$-value $=0.01)$. Age-wise distribution of organisms is shown in Table 2 .

\begin{tabular}{|c|c|c|}
\hline Age group & Pseudomonas Aeruginosa $n(\%)$ & Klebsiella Pneumonae n(\%) \\
\hline$<10$ years & $63(76.8 \%)$ & $47(23.2 \%)$ \\
\hline$\geq 11$ years & $18(62 \%)$ & $11(38 \%)$ \\
\hline
\end{tabular}

TABLE 2: Age-wise distribution of the organisms

The males were infected more as compared to females and the organism seen the most on culture was Pseudomonas aeruginosa $(\mathrm{P}$-value $=0.04)$. The gender distribution of organisms is shown in Table 3 . 


\section{Cureus}

\begin{tabular}{|c|c|c|}
\hline Gender & Pseudomonas Aeruginosa n(\%) & Klebsiella Pneumonae n(\%) \\
\hline Male & $58(63 \%)$ & $34(37 \%)$ \\
\hline Female & $24(51 \%)$ & $23(49 \%)$ \\
\hline
\end{tabular}

TABLE 3: Gender distribution of the organisms

\section{Discussion}

CSOM is a chronic infection of the middle ear, with otorrhoea through a perforated tympanic membrane. It is the most common ear infection in children under the age of 10 years [12]. Our study confirms these findings.

There is a variability in the number of participants recruited in the studies worldwide. Two studies enrolled only 68 patients for CSOM [13, 14]. Another study carried out in 1991 included 360 patients for CSOM [15]. We included 139 patients, keeping in mind the prevalence in our region. Males were 92 (66.19\%) while females were 47 (33.81\%) in our project. In contrast to this, females were more prone to contracting CSOM as demonstrated by one study [16].

In this study, patients were divided into two age groups i.e., less than equal to 10 years and more than or equal to 11 years. In contrast, one study carried in 2011 in Nepal included 6005 patients of CSOM but distribution varied with respect to age groups, ranging from less than 10 years to more than 50 years [17]. Among the 139 enrolled patients, the frequency of only two pathogens (Pseudomonas aeruginosa and Klebsiella pneumonae) was observed. In contrast, previous studies observed various aerobic and anaerobic pathogens for CSOM. Our findings were similar to one study which demonstrated Pseudomonas aeuruginosa as the predominant organism (50\%) in CSOM [18].

This study has various limitations. It is a single-center study and there were only two organisms isolated in the swab cultures. No effect of antibiotics was observed in the study and no complications were seen. A large-scale multicenter study is needed in our region to accurately describe the causality of CSOM.

\section{Conclusions}

This study helped in identifying the causality of the most common bacteria of CSOM at our setup. Almost all the patients had either of the two organisms, Pseudomonas aeruginosa or Klebsiella pneumonae. It will help in the appropriate prescription of antibiotics for the treatment of CSOM. To our knowledge, this is the first study to see the causal relationship of CSOM with the organism in our region.

\section{Additional Information \\ Disclosures}

Human subjects: Consent was obtained by all participants in this study. Research Cell Lahore Medical And Dental College issued approval LMDC/IRB/1/7/20. It is certified that Dr. Talha Laique has submitted a research proposal entitled 'Causality of Chronic Suppurative Otitis Media' for consideration. The proposal has fulfilled all potential requirements. The Research and Ethics Committee has no objection and therefore, approves and accepts the proposal. . Animal subjects: All authors have confirmed that this study did not involve animal subjects or tissue. Conflicts of interest: In compliance with the ICMJE uniform disclosure form, all authors declare the following: Payment/services info: All authors have declared that no financial support was received from any organization for the submitted work. Financial relationships: All authors have declared that they have no financial relationships at present or within the previous three years with any organizations that might have an interest in the submitted work. Other relationships: All authors have declared that there are no other relationships or activities that could appear to have influenced the submitted work.

\section{References}

1. Matsuda Y, Kurita T, Ueda Y, Ito S, Nakashima T: Effect of tympanic membrane perforation on middle-ear sound transmission. J Laryngol Otol. 2009, 123:81-89. 10.1017/S0022215109005155

2. Rupa V, Jacob A, Joseph A: Chronic suppurative otitis media: prevalence and practices among rural South Indian children. Int J Pediatr Otorhinolaryngol. 1999, 48:217-221. 10.1016/s0165-5876(99)00034-8

3. Muhaimeid H, Zakzouk S, Bafaqeeh S: Epidemiology of chronic suppurative otitis media in Saudi children . Int J Pediatr Otorhinolaryngol. 1993, 26:101-108. 10.1016/0165-5876(93)90015-u

4. van der Veen EL, Schilder AG, van Heerbeek N, Verhoeff M, Zielhuis GA, Rovers MM: Predictors of chronic suppurative otitis media in children. Arch Otolaryngol Head Neck Surg. 2006, 132:1115-1118. 10.1001/archotol.132.10.1115 
5. Morris P: Chronic suppurative otitis media. BMJ Clin Evid. 2012, 2012:0507.

6. Kisembo P, Mugwanya F, Atumanya P, et al.: Prevalence of ear infections in first year children of primary schools in a Western Ugandan community. Afr J Biomed Res. 2018, 21:117-122.

7. Poorey VK, Lyer A: Study of bacterial flora in csom and its clinical significance . Indian J Otolaryngol Head Neck Surg. 2002, 54:91-95. 10.1007/BF02968724

8. Prakash R, Juyal D, Negi V, Pal S, Adekhandi S, Sharma M, Sharma N: Microbiology of chronic suppurative otitis media in a tertiary care setup of Uttarakhand state, India. N Am J Med Sci. 2013, 5:282-287. 10.4103/1947-2714.110436

9. Wright D, Safranek S: Treatment of otitis media with perforated tympanic membrane. Am Fam Physician. 2009, 79:650-654.

10. Gomaa MA, Abdel Karim AR, Abdel Ghany HS, Elhiny AA, Sadek AA: Evaluation of temporal bone cholesteatoma and the correlation between high resolution computed tomography and surgical finding. Clin Med Insights Ear Nose Throat. 2013, 6:21-28. 10.4137/CMENT.S10681

11. Sandhu N, Thomson D, Stang A: In children with chronic suppurative otitis media, should one prescribe topical or systemic antibiotics?. Paediatr Child Health. 2012, 17:385-386.

12. Mittal R, Lisi CV, Gerring R, et al.: Current concepts in the pathogenesis and treatment of chronic suppurative otitis media. J Med Microbiol. 2015, 64:1103-1116. 10.1099/jmm.0.000155

13. Olusanya BO, Newton VE: Global burden of childhood hearing impairment and disease control priorities for developing countries. Lancet. 2007, 369:1314-1317. 10.1016/S0140-6736(07)60602-3

14. Venekamp RP, Damoiseaux RA, Schilder AG: Acute otitis media in children . BMJ Clin Evid. 2014, 2014:0301.

15. Rupa V, Raman R: Chronic suppurative otitis media: complicated versus uncomplicated disease . Acta Otolaryngol. 1991, 111:530-535. 10.3109/00016489109138379

16. Brook I: The role of anaerobic bacteria in chronic suppurative otitis media in children: implications for medical therapy. Anaerobe. 2008, 14:297-300. 10.1016/j.anaerobe.2008.12.002

17. Thornton D, Martin TPC, Amin P, Haque S, Wilson S, Smith MCF: Chronic suppurative otitis media in Nepal: ethnicity does not determine whether disease is associated with cholesteatoma or not. J Laryngol Otol. 2011, 125:22-26. 10.1017/S0022215110001878

18. Neeff M, Biswas K, Hoggard M, Taylor MW, Douglas R: Molecular microbiological profile of chronic suppurative otitis media. J Clin Microbiol. 2016, 54:2538-2546. 10.1128/JCM.01068-16 